\title{
Market challenges for local specialty crop producers during the early phase of COVID-19 in North Carolina
}

\author{
Hannah Dankbar, ${ }^{a}$ Ethan Phillips, ${ }^{\mathrm{b}}$ Angel Cruz, ${ }^{\mathrm{c}}$ \\ Emma Volk, ${ }^{\mathrm{d}}$ and Mark Hoffmann e* \\ North Carolina State University
}
THE IMPACT OF COVID-19 ON FOOD SYSTEMS COSPONSORED BY INFAS:

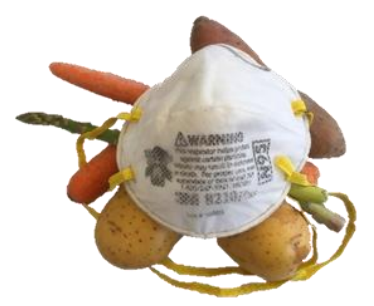

Inter-institutional

Network for

Food and

Agricultural

Sustainability

Submitted November 9, 2020 / Revised March 18 and June 16, 2021 / Accepted June 23, 2021 /

Published online August 21, 2021

Citation: Dankbar, H., Phillips, E., Cruz, A., Volk, E., \& Hoffmann, M. (2021). Market challenges for local specialty crop producers during the early phase of COVID-19 in North Carolina. Journal of Agriculture, Food Systems, and Community Development, 10(4), 229-239. https://doi.org/10.5304/jafscd.2021.104.004

Copyright (C) 2021 by the Authors. Published by the Lyson Center for Civic Agriculture and Food Systems. Open access under CC-BY license.

\begin{abstract}
In March of 2020, as the number of COVID-19 cases increased in North Carolina (NC), the state encouraged people to stay at home; this included closing restaurants and canceling large events, as well as reducing the number of people gathering. The economic and health crises created by COVID-19 forced specialty crop producers who sell to local markets, such as restaurants and institutions, to pivot their marketing plans as the growing season began to ramp up. This article reports the responses to the first in a series of producer surveys assessing the impact of the economic and health crises on crop production, market channels, and producer concerns during
\end{abstract}

${ }^{a}$ Hannah Dankbar, Local Foods Program, College of Agriculture and Life Sciences (CALS), North Carolina State University; Raleigh, NC USA; hcdankba@,ncsu.edu

${ }^{\mathrm{b}}$ Ethan Phillips, Center for Environmental Farming Solutions (CEFS), North Carolina State University, Raleigh NC USA; ethanp5@live.unc.edu

c Angel Cruz, Center for Environmental Farming Solutions (CEFS), North Carolina State University, Raleigh NC USA; aecruz@ncsu.edu one of the most insecure times in modern history. Results show that producers who could pivot their marketing plans mostly increased sales through online channels and farm stands. However, almost $50 \%$ of the usual market channels were reported to be closed due to COVID-19. Additionally, most producers voiced concerns about economic and health safety in the immediate future. To address these concerns as the pandemic unfolded, there was a need for trusted information. Respondents reported that they rely on Extension and other government agencies for this information and updates regarding the pandemic. This survey captured the early impacts of the COVID-19 pandemic on the specialty crop-producing industry in NC. Additional surveys will provide information on how the pandemic evolved during 2020.

\footnotetext{
d Emma Volk, Department of Horticultural Science, CALS, North Carolina State University, Raleigh NC USA; evolk@,ncsu.edu

e* Corresponding author: Mark Hoffmann, Department of Horticultural Science, CALS, NCSU, 2721 Founders Drive, Campus Box 7605; Raleigh NC 27695-7605 USA; +1-919352-8006; mhoffma3@ncsu.edu
} 


\section{Keywords}

COVID-19, Horticulture Crops, Specialty Crop

Production, Local Food Systems, Pandemic

\section{Introduction}

In March of 2020, it was more than difficult to foresee the full extent of COVID-19 and the impact it would have on our local and global food systems. In NC, a statewide stay-at-home order went into effect on March 30, 2020, and lasted until May 22, 2020 (NC Executive Order 121, 2020). Additionally, due to regulation on the size of gatherings, many facilities were forced to close, including schools, offices, restaurants, bars, salons, gyms, and daycare centers. Prior to the pandemic, Americans consumed approximately $34 \%$ of all meals outside the home, and $50 \%$ of household food budgets were spent on meals outside the home (Saksena et al., 2018). While the closure of institutions and restaurants minimized the spread of COVID-19 infections, it led to dramatic shifts in the way people access and consume food. These shifts in habits, which happened almost overnight, created major disruptions in food supply chains across the country (Anderson, 2020; Havice et al., 2020; Hendrickson, 2020).

The local food economy in the United States has an estimated commodity value of more than US $\$ 8.7$ billion per year (U.S. Department of Agriculture National Agricultural Statistics Service [USDA NASS], 2015, 2019) and is mainly driven by small and medium-sized farming operations. Approximately one-third of all specialty crop producers in the U.S. are considered small-scale producers, with an annual income of less than US $\$ 250,000$ (USDA NASS, 2019) and 33\% of all revenue generated through direct-to-consumer sales (USDA NASS, 2015). In NC, the local food economy is an important revenue stream for many farms and is a source of fruits and vegetables for consumers across the state. Approximately $9 \%$ of farms in NC sell directly to consumers, generating about US\$70 million annually (MacDonald, 2021).
Direct-to-consumer market channels include products sold through farmers markets, farm stands and stores, U-pick operations, online sales, and community supported agriculture (CSA) (MacDonald, 2021). To help consumers access these products, the N.C. Department of Agriculture and Consumer Services (NCDA \& CS) operates four farmers markets throughout the state. In addition, there are an estimated 235 other farmers markets across NC (NCDA \& CS, 2020). At the beginning of the pandemic, especially in April of 2020, many farmers markets operated at reduced capacity in $\mathrm{NC}$.

Within the span of a few days, many specialty crop producers in NC lost their primary markets and important revenue streams due to COVID-19 related local and statewide orders. Therefore, producers suddenly — and urgently — needed to identify new markets and adopt new safety measures (White, 2021). Early surveys on the impact of COVID-19 on food systems raised major concerns about the economic vulnerability of producers, especially of small-scale producers, impacted by pandemic-related recommendations and orders (Carolina Farm Stewardship Association [CFSA], 2020; Cranfield, 2012; Hobbs, 2020; Lusk et al., 2020). While the adaptability of small-scale producers can lead to increased resilience of local food systems overall, single producers are also more vulnerable to damaging economic losses due to COVID-19 (CFSA, 2020; Hobbs, 2020). Specialty crop producers had to adapt to new market channels quickly. In the early months of the COVID-19 pandemic, the N.C. Cooperative Extension Service (NCCES) and other Extension services across the nation were challenged to identify needs, adapt programming, and address the rapidly evolving preferences of consumers and producers (Patillo et al., 2021). Some of these needs resulted from fastchanging demand within the food system and specific market channels and supply chains.

Therefore, the Center for Environmental Farming Systems (CEFS), ${ }^{1}$ in collaboration with

\footnotetext{
${ }^{1}$ The Center for Environmental Farming Systems (CEFS) was established in 1994 as a partnership among NC State University, NC Agricultural and Technical State University, and the NC Department of Agriculture and Consumer Services. CEFS develops and promotes just and equitable food and farming systems that conserve natural resources, strengthen communities, improve health outcomes, and provide economic opportunities in NC and beyond.
} 
the Department of Horticultural Science and the Local Foods Program at NC State University, developed a statewide specialty crop producer survey in late April 2020, aiming to assess the impact of the COVID-19 pandemic on farm safety, market avenues, and producer needs. We collaborated with the CFSA, which also surveyed NC and South Carolina. However, our survey focused solely on specialty crop producers in NC. Here we summarize the results of this survey and discuss changes to online and direct-to-consumer markets of local specialty crop producers and NCCES responses during the early phase of the COVID-19 pandemic in NC.

\section{Methods}

Several Extension Specialists with the Department of Horticultural Science (see Acknowledgments), the Center of Environmental Farming Systems (CEFS), and the Local Foods Program at NC State University developed the survey instrument. The survey aimed (1) to assess the impact of COVID19 on farm safety and the market distribution of local specialty crop producers in NC, and (2) to assess specific COVID-19 related extension needs of specialty NC producers.

The survey instrument contained nine questions in five sections (Table 1). The first section asked for general farm demographics, including farm size, types of crops grown, and market outlets utilized before the COVID-19 pandemic. The survey instrument then moved on to the second set of questions, which sought to determine how certain market outlets were initially affected (i.e., an increase in sales, a decrease in sales, no change, or a complete shutdown) by COVID-19. The third set of questions focused on the challenges producers faced at the start of the pandemic. The fourth set of questions asked what measures the farms were planning to take in the coming weeks in response to the COVID-19 pandemic. The last set of questions was specific to NC State Extension-question nine asked how Extension could assist producers and where each participant found COVID-19 information.

The survey was built in Qualtrics XM (SAP, Cary, NC) and was web-based (no print copies were distributed). It was anonymous, and no incentives were offered for completion. None of the answers was forced, and it took 7 to 8 minutes on average to complete the survey. The initial landing page provided a brief overview of the survey and asked for consent to utilize the data anonymously for research purposes. The survey was initially distributed on April 23, 2020, and data collection was closed on May 13, 2020. Before distribution, the survey was approved by the Office for Research and Compliance at NC State University (IRB Protocol Number 21001).

The main objective of this project is to evaluate the impact of COVID-19 on producers who sell to local markets. The survey was intended to reach NC specialty crop producers who did not typically rely on agritourism for any percentage of their revenue stream; any respondent who indicated that they had a restaurant, tasting room, winery, event space, or other agritourism offering was not included in statistical analyses of the survey results. To get the most accurate picture of these impacts, we decided to remove businesses that rely on these revenue streams.

The survey description and link were distributed through multiple email listservs and blogs that reach our desired demographic — specialty crop producers in NC. The following distribution channels were used: NC State Extension COVID-19 Resource page; NC State Horticulture Extension Portals; NC State berry, grape, vegetable, hemp, and herb producer listservs; NC Strawberry Association; NC Vegetable Grower Association; NC Muscadine Grape Association; and all NC Cooperative Extension Horticulture and Local Foods Agents.

All survey questions were downloaded from Qualtrics without identifiers and then analyzed using R scripts. Data cleaning and preliminary analysis using $\mathrm{R}$ were completed in RStudio version 1.2.5033. The resultant data frames were downloaded as CSV files onto a secured, remote OneDrive server hosted through the University of North Carolina at Chapel Hill. Microsoft Excel 2019 (Microsoft, Seattle, Washington) was used for further analysis and graphic production. 
Table 1. Overview of Questions and Answers of the April 2020 COVID-19 NC Producers Survey

The survey was developed in Qualtrics, distributed online, and open from April 23, 2020, to May 13, 2020. Respondents were not required to answer each question.

\begin{tabular}{|c|c|c|c|}
\hline \multicolumn{2}{|c|}{ Question } & \multirow{2}{*}{$\begin{array}{l}\text { Answer Choices } \\
\text { Small-scale farm (0-100 acres); Mid-size farm (100-300 acres); } \\
\text { Mid-size farm (300-500 acres); Large-scale farm (>500 acres) }\end{array}$} & \multirow{2}{*}{$\begin{array}{l}\begin{array}{c}\text { Valid } \\
\text { responses }\end{array} \\
124\end{array}$} \\
\hline 1 & $\begin{array}{l}\text { How would you describe the size of } \\
\text { the farmed land (all crops combined) } \\
\text { you own or manage? (select all that } \\
\text { apply) }\end{array}$ & & \\
\hline 2 & $\begin{array}{l}\text { What crops do you grow on your } \\
\text { farm? (select all that apply) }\end{array}$ & $\begin{array}{l}\text { Vegetables (peppers, tomatoes, cucumbers); Vegetables (squash, } \\
\text { melons, pumpkins); Herbs; Flowers; Potatoes (sweet potatoes, } \\
\text { white potatoes); Berries (strawberry, caneberry, blueberry); Grapes } \\
\text { (fresh market, processing); Tree Fruit (apples, peaches, pecans); } \\
\text { Hemp; Other Vegetables; Other Fruit }\end{array}$ & 120 \\
\hline 3 & What is true for you? & $\begin{array}{l}\text { We had to close part of the business; We had to close the entire } \\
\text { business; We have more business than the same time last year; We } \\
\text { have the same amount of business compared to this time last year }\end{array}$ & 117 \\
\hline 4 & $\begin{array}{l}\text { What were your market outlets Pre- } \\
\text { COVID-19 (percentage of sales) }\end{array}$ & $\begin{array}{l}\text { U-Pick (__\%); Farm Stand/Farm Store/Roadside/Pick-Up (__\%); } \\
\text { Wholesale to grocery stores (__\%); Farmers Markets (__\%); Sale to } \\
\text { restaurants/schools or other institution (__\%); Online sales/delivery } \\
(\ldots \%)\end{array}$ & 117 \\
\hline 5 & $\begin{array}{l}\text { If anything has changed, how has } \\
\text { your typical market outlet been } \\
\text { affected by COVID-19, compared to } \\
\text { this time last year? }\end{array}$ & $\begin{array}{l}\text { U-Pick; Farm Stand/Farm Store/Roadside/Pick-Up; Wholesale to } \\
\text { grocery stores; Farmers Markets; Sale to restaurants/schools or } \\
\text { other institution; Online sales/delivery }\end{array}$ & 102 \\
\hline 6 & $\begin{array}{l}\text { What challenges do you currently } \\
\text { face due to the COVID-19 pandemic? } \\
\text { (select all that apply) }\end{array}$ & $\begin{array}{l}\text { Food safety; Loss of income or reduced sales; Visitor, customer, } \\
\text { staff safety; Availability of labor supplies; Availability of labor; } \\
\text { Impact on community health; Impact on personal and/or farmer } \\
\text { health; Duration of restriction and economic impact; How can I } \\
\text { follow new guidelines and best practices; None; Other (please } \\
\text { specify) }\end{array}$ & 120 \\
\hline 7 & $\begin{array}{l}\text { What measures do you plan to take in } \\
\text { the coming weeks due to the COVID- } \\
19 \text { pandemic? (select all that apply) }\end{array}$ & $\begin{array}{l}\text { Close business completely; Transition to takeout or online services } \\
\text { or curbside exclusively; Using more personal protection (hand } \\
\text { sanitizer, wearing masks, etc.); Implement more social distancing of } \\
\text { staff and customers; Reduce staff/labor; None of the above; Other } \\
\text { (please specify) }\end{array}$ & 104 \\
\hline 8 & $\begin{array}{l}\text { How do you expect NC State } \\
\text { Extension to assist you? (select all } \\
\text { that apply) }\end{array}$ & $\begin{array}{l}\text { Provide advice on best practice to keep operations open and safe; } \\
\text { Provide frequent updates and information on the situation; Help } \\
\text { identify new markets for your product; Assist with changes in } \\
\text { operations; Be at the extension station or in the field with farmers; } \\
\text { No expectations; Other (please specify) }\end{array}$ & 121 \\
\hline 9 & $\begin{array}{l}\text { Where do you get your information } \\
\text { regarding the COVID-19 pandemic? } \\
\text { (select all that apply) }\end{array}$ & $\begin{array}{l}\text { NC State Extension; Extension service of other university(ies); } \\
\text { Newsletters; Crop associations; News (national/local); Social media } \\
\text { (Facebook, Twitter, etc.); Government (local/national) e.g. CDC, } \\
\text { FDA, etc.; Nonprofit organizations; Friends and neighbors; Other } \\
\text { (please specify) }\end{array}$ & 121 \\
\hline
\end{tabular}




\section{Results}

\section{Demographics}

Out of 198 responses, we eliminated 57 responses for not indicating farm size and crops grown (nonvalid). We further eliminated 17 responses from operations which included agritourism revenue streams. A total of 124 valid responses were counted on the day of survey closure.

Responses were considered valid if the respondents answered questions 1 and 2 (Table 1). These two questions were used to identify possible connections between farms' COVID-19 responses and their demographics. Out of the 124 valid responses, 96 respondents identified as small farms (0-100 acres), 15 identified as mid-sized farms (100-500 acres), and five identified as large-scale farms $(500+$ acres). Vegetables (peppers, tomatoes, cucumbers) were the most common crops grown by survey respondents $(n=71)$. Vegetables (squash, melons, pumpkins) followed closely behind, with 62 respondents indicating that their operations

\section{Figure 1. Business Volume During April/May 2020 Compared to the Previous Year}

Survey respondents were asked, "What is true for you?" They were given four response options to determine whether their market outlets experienced increases, decreases, or no changes in activity compared to the same time the previous year (2019). Respondents could select one, multiple, or none of the answers provided. Total $n=117$.

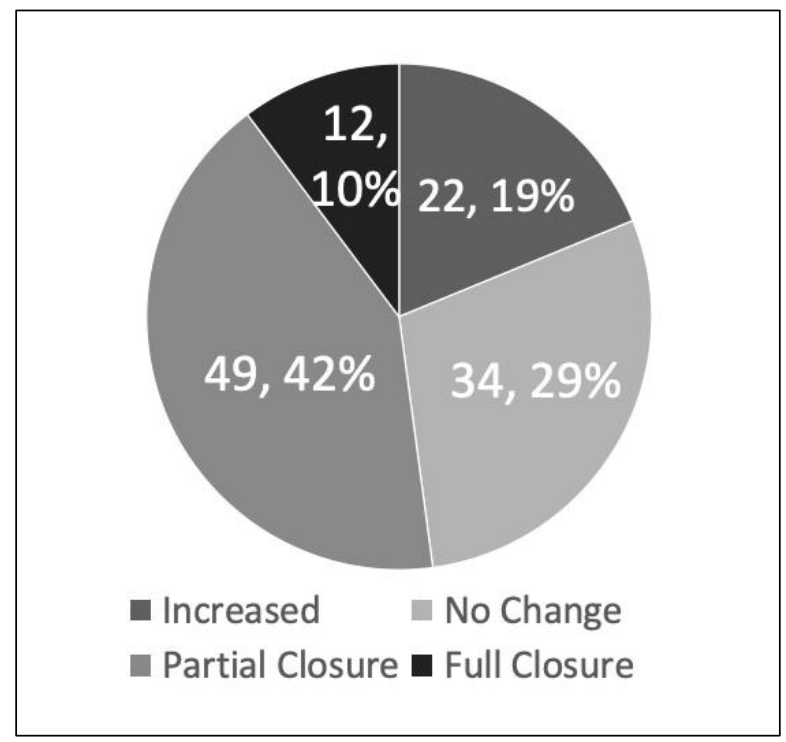

grew these crops. After vegetables, berries were the third most common crop $(n=51)$.

\section{Impact of COVID-19 on Market Distributions of Specialty Crop Operations in NC}

Several questions asked producers to assess the impact of COVID-19 on the market distribution of specialty crop-producing operations in NC. The survey provided four options to evaluate general changes in business volume (Question 3, Table 1). Figure 1 highlights how operations were initially impacted by COVID-19 $(n=117)$. The plurality of farming operations $(41.88 \%(n=49))$ experienced a partial closure of their business, while roughly a quarter $(29.06 \%(n=34))$ experienced no change in business compared to the same time last year. Moreover, $18.80 \%(n=22)$ experienced an increase in business compared to the same time the previous year, while $10.26 \%(n=12)$ experienced a full closure of their business.

When asked about changes to market outlets, $87.80 \%(n=36)$ of producers reported a partial or complete loss of business with restaurants and schools. $66.67 \%(n=32)$ had less business in the $\mathrm{U}$ Pick market, and $61.76 \%(n=21)$ experienced decreased or closed business with wholesale markets. However, $32.79 \%(n=20)$ reported an increase in farm stand outlets, and $51.35 \%(n=19)$ reported an increase in using online platforms for fresh produce sales (Figure 2). Only 10\% of operations were engaged in online sales before the pandemic occurred (Question 4, Table 1, data not shown).

\section{Producers' Immediate Reactions to COVID-19}

Two questions were asked to find out more about the sense of responsiveness and concerns related to economic well-being and health security. When asked about the challenges producers faced during the beginning of the COVID-19 pandemic (Question 6, Table 1, 2), $67.50 \%(n=81)$ reported a loss of income (Table 2$)$, and $60.83 \%(n=73)$ reported that the duration of COVID-19 regulations posed difficulties for their farming operation. In addition, $50.83 \%(n=61)$ of producers were challenged by protecting the safety of their customers and staff, and $36.67 \%(n=44)$ worried about their personal health (Table 2). The availability of labor challenged $35.00 \%$ of respondents $(n=42)$. About one- 
quarter of respondents $(25.00 \%, n=30)$ were challenged in implementing new regulations on their farming operations. Less than a quarter of respondents were challenged by food safety $(19.17 \%$ $(n=23))$, availability of supplies $(18.33 \%(n=22))$, or the impact of COVID-19 on community health $(17.50 \%(n=21))$.

When asked what measures producers were planning to take in the coming weeks due to the COVID-19 pandemic (Question 7, Table 1), producers responded that they planned to implement more personal protection equipment (73.08\% $(n=76))$, use more social distancing between staff and customers $(62.50 \%(n=65))$, develop online or pick-up services $926.92 \%(n=28))$, and reduce labor and staff $(23.08 \%(n=24))$.

\section{Specific COVID-19 related extension} needs in NC

The survey's eighth question asked, "How do you expect NC Cooperative Extension to help you?" Respondents were allowed to pick one, multiple, or none of the following responses: (1) Provide updates and information on the pandemic; (2) Provide advice on best practices to keep operations open and safe; (3) Be at the extension station or in the field with producers; (4) Provide operational assistance; (5) Other; (and/or 6) No expectations (Table 1). Of the 121 respondents who answered this question, $60.33 \%(n=73)$ expected NCCES to provide updates and information on the pandemic, and $51.24 \%(n=62)$ also wanted advice on the best practices to keep farming operations open and safe. Less than half wanted extension agents to be at the extension station/in the field with producers and provide operational assistance (Figure 3). Those who answered "other" could explain what types of assistance they desired. These answers included: information on grants to support affected

\section{Table 2. Producers' Challenges During April/May 2020}

Survey respondents were asked, "What challenges do you currently face due to the COVID-19 pandemic?" and were given 11 answer options (Table 1). Indicated here are the percentage of businesses and number per responses per answer. Respondents could select one, multiple, or none of the answers provided. Total $n=120$.

\begin{tabular}{lll}
\hline Concern & \multicolumn{1}{c}{$\begin{array}{c}\text { Percent (\%) of } \\
\text { Producers }\end{array}$} & $\mathrm{n}$ \\
\hline Loss of Income & $67.5 \%$ & 81 \\
Duration of restrictions & $60.83 \%$ & 73 \\
Visitor, customer, staff safety & $50.83 \%$ & 61 \\
Personal health & $36.67 \%$ & 44 \\
Availability of labor & $35.00 \%$ & 42 \\
New guidelines & $25.00 \%$ & 30 \\
Food safety & $19.17 \%$ & 23 \\
Availability of supplies & $18.33 \%$ & 22 \\
Impact on community health & $17.50 \%$ & 21 \\
\hline
\end{tabular}

producers, meetings for "vine producers" to discuss vineyard-related issues, and sharing information on the implications of COVID-19 on food production with state and federal agencies.

The survey's ninth question asked, "Where do you get your information regarding the COVID-19 pandemic?" Respondents were given nine possible 


\section{Figure 3. Producers' Needs from NC State Cooperative Extension}

Survey respondents were asked, "How do you expect NC Cooperative Extension Service to help you?". Indicated is the percentage of respondents. Total $n=121$.

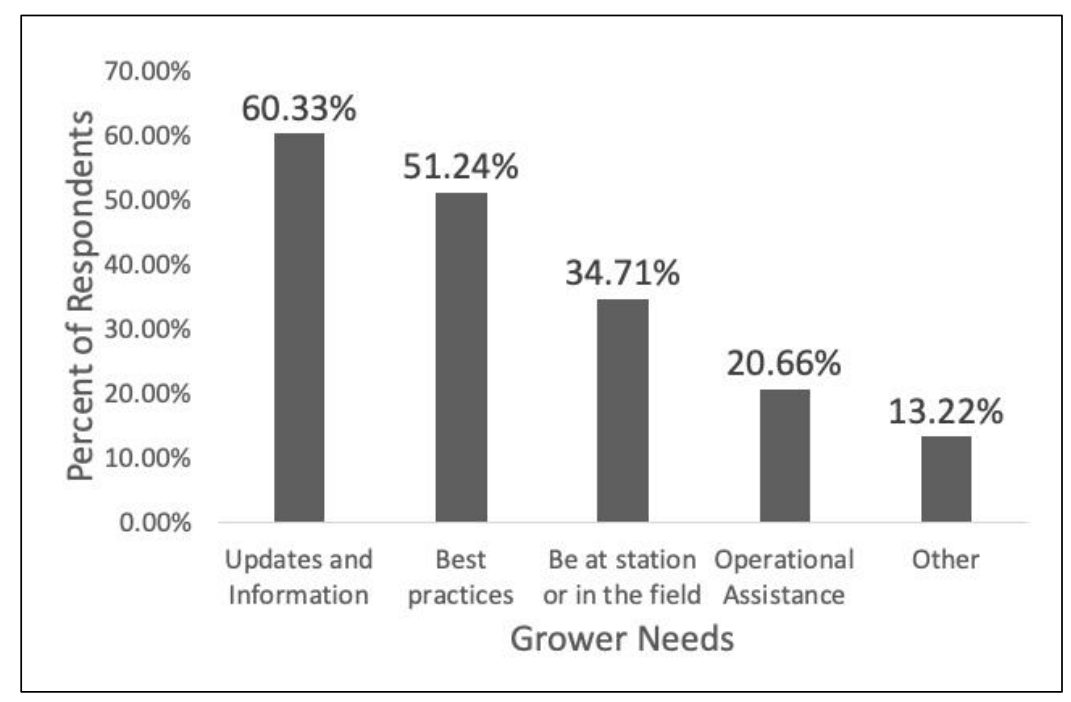

ers over an unfolding economic and health crisis, as well as the early economic impact on the specialty crop farming community in NC. By assessing these immediate reactions and responses, we hope to contribute knowledge to shape an optimized and robust crisis extension and policy response in $\mathrm{NC}$ in the future.

Impact of COVID-19 on Market Distribution Channels of Specialty Crop Operations in NC

While more than $50 \%$ of all producers who responded to the survey reported full or partial closures due to COVID-19, 35\% did not experience any changes. In addition, more than $20 \%$ experienced answers (Table 1). A majority, $82.64 \%(\mathrm{n}=100)$ of respondents, indicated that they received their information from national or local news sources. Governmental and NCCES sources were found to provide $61.16 \%(n=74)$ and $49.59 \%(n=60)$ of producers with information regarding COVID-19, respectively. The remaining responses decreased in popularity starting with social media $(33.06 \%$ $[\mathrm{n}=40])$, newsletters $(31.40 \%(\mathrm{n}=38)$, friends and neighbors $(20.66 \%(\mathrm{n}=25))$, crop associations $(16.53 \%(\mathrm{n}=20))$, and other university extension agencies $(19.01 \%(n=23))$. Those who responded "Other" explained that they got their information from research publications or international news organizations.

\section{Discussion}

North Carolina took a leading role among the Southern states in carrying out early stay-at-home orders and statewide facemask requirements and was one of the last states in the South to implement re-opening phases (NCGOV, n.d.). While COVID-19 has long-lasting impacts on the economy of small and medium-sized farms, this study focuses on the immediate impacts of early COVID-19 regulations on specialty crop producers over the weeks of April and the beginning of May 2020. We document both the concerns of produc- an increase in business due to COVID-19 (Figure 1). Most sales loss was reported with restaurants, schools, traditional U-Pick operations, and grocery stores (Figure 2); this finding was expected. An important note is that producers had to find places to sell their products with little time to pivot as the growing season was ramping up due to the sudden closure of restaurants and events. These results correspond with a Carolina Farm Stewardship Association (CFSA) survey over the same period with producers in both $\mathrm{NC}$ and South Carolina, including livestock and value-added producers. CFSA utilized general traffic to their website and their member listserv for survey participation, while our survey was disseminated through various channels, including grower associations and cooperative extension (see above). The CFSA survey showed a decrease in almost all market channels for small and medium-sized farms (CFSA, 2020) and reported an increase in 'other direct-to-consumer sales.' This aligns with a May 2020 Congressional Report that stated that the U.S. fruit and vegetable industry considered direct-to-consumer market channels as an alternative distribution option to meet demand shortfalls from traditional market channels (Johnson, 2020). In the reported survey, online sales and farm stands became important market channels during the stay-at-home 
orders and business closures in March and April 2020 in NC (Figure 2). 10\% of our respondents reported utilizing online sales before the pandemic, but $45 \%$ of respondents reported increased sales from online platforms during the pandemic. This demonstrates that producers quickly adopted new technology and approaches to find new customers and sales outlets for their products (Lemos \& Ackoff, 2020, O'Hara \& Low, 2020). Farm stands proved to be another important market channel for specialty crop producers during the stay-at-home order, with $30 \%$ of producers reporting increased sales at farm stands (Figure 2).

However, these cases stand in contrast to the $55 \%$ of surveyed producers that indicated they lost business compared to the same time in 2019. Potential reasons for this difference may include farm size (in terms of total sales and not just acreage), availability of labor, access to markets and technology, technology literacy, and prior marketing experience. Our survey findings were reinforced by the CFSA survey (CFSA, 2020), which showed that approximately $50 \%$ of farms increased direct-to-consumer sales while approximately $40 \%$ experienced decreased sales, with the remainder of farms remaining the same.

Direct-to-consumer supply chains have generally proven to be more flexible and adaptable to system-wide changes or threats than global supply chains (Cullen, 2020; Johnson, 2020). However, our data indicate a more complicated story: more than half of all producers could not react to new circumstances, and only about one-third were able to increase business by shifting to new market channels. Such results are unsustainable on a longterm scale, and we advocate for policies that improve the adaptability and flexibility of small farms and local food producers in the future. Such preparedness can include ongoing training programs, the development of high-speed internet infrastructure (CFSA, 2020), expanding and restructuring extension programs, and improved labor training and availability (Low et al., 2015; O'Hara \& Low, 2020). More than $50 \%$ of farms that sell direct to consumers are in metropolitan counties (O'Hara \& Low, 2020). Higher population levels within 50 miles of a farm increase the likelihood of participating in direct-to-consumer mar- kets (O'Hara \& Lin, 2019). Farms in NC located in more rural counties may not have had enough consumer traffic to justify increasing direct-to-consumer sales.

\section{Producers' Immediate Concerns related to COVID-19}

Factors such as input price variability, uncertain weather and climate patterns, yield variability, and price fluctuations make operating a farm business an especially difficult and risky venture (Low et al., 2015). In 2020, the chaos and uncertainty surrounding the COVID-19 pandemic made running a farm even more difficult.

Our survey asked what challenges NC producers faced since COVID-19 regulations were put in place and the major measures producers were planning to implement in the immediate future (Questions 6 and 7, Table 1, Table 2). When asked about major challenges since the onset of the pandemic, economic concerns outweighed health concerns. Two out of the three most common answers were related to economic challenges (Table 2): (\#1) loss of income, (\#2) duration of restrictions, and (\#3) health concerns (Visitor, Consumer, and Staff safety). Personal safety (\#4) was only important to $36 \%$ of the respondents, and labor availability (\#5) to $35 \%$. These answers indicate that even if producers could shift market avenues quickly, those changes were still costly and might have generated a net loss of income. These results are supported by the CFSA survey, in which many producers also reported a loss of income during the first month of the COVID-19 pandemic in NC and SC (CFSA, 2020).

However, when looking into the immediate future, health concerns were prioritized over economic concerns. Two out of the top three answers were related to health concerns, with 76 producers planning to implement increased personal protection equipment (\#1) and 65 planning to use more social distancing (\#2). Only 28 producers were planning to develop online services (\#3). So while producers are aware of personal, staff, and consumer safety, economic challenges were prioritized during the first month of the pandemic. Concerns over economic loss might have restricted the implementation of health and safety measures. However, more research is required to understand the 
underlying factors surrounding farm management decision-making during COVID-19 or other system-wide crises in the future. A better understanding of factors that impact local supply chain dynamics during a public health crisis is essential for informed decision-making and local, regional, and federal policy recommendations.

\section{Recommendations and Conclusion}

The COVID-19 pandemic is a worldwide economic and health crisis that left more than 500,000 people dead in the U.S. alone. At the beginning of the COVID-19 pandemic, government regulations rapidly shifted food supply chains globally and locally. This survey was conducted to understand the initial impact of COVID-19 on specialty crop producers in NC during the first month of stay-athome orders. While approximately one-third of producers could adapt to other direct-to-consumer market channels, $50 \%$ reported an overall loss of business, and more than $80 \%$ reported a loss of income. Additionally, economic well-being was the focus of many producers during the first month of the pandemic in NC, while health concerns were prioritized for future actions. Producers also identified a need for trustworthy information. Within NC, NCCES assisted in fulfilling this need. However, our results demonstrate critical financial, policy, and education needs for local, regional, and federal governments and Cooperative Extension Services in the U.S.

Based on the survey results, we believe there is a need for farm-specific financial and policy responses, which could entail, for example, subsidizing farm-specific education efforts tailored to fact-based information on COVID-19, enforcing COVID-19 safe workspaces on farms and in packing houses, and funding programs to develop safe farming environments and public education on local foods. Such responses could facilitate the economic viability of local farms, eventually leading to the prevention of illness or death of farmers and farmworkers due to COVID-19.

Generally, we are encouraged by the adapta- tion and resiliency of producers across $\mathrm{NC}$ during the early stage of the COVID-19 pandemic. However, we believe that Cooperative Extension should play a larger role in crisis-related outreach and education efforts in the future. The long-standing integration of Cooperative Extension in rural communities across the U.S. and its core mission of education and knowledge transfer has proven to be a source of trust to communities in NC. Our survey showed that almost $50 \%$ of respondents also used NCCES as a source for COVID-19 related news. Cooperative Extension bears the potential to broaden its mission to other important areas of education related to global crisis management. These areas could reach from water-saving strategies over climate change to education on racial equity. This is a unique opportunity to explore new possibilities for the future mission of Cooperative Extension, which extension professionals, administrators, and policy-makers should not miss.

On the day the survey was closed (May 13, 2020), 16,351 people in NC had tested positive for COVID-19, and 625 people in NC had lost their lives due to the disease. While this publication focuses on the economic hardship that COVID-19 brought to the farming community in $\mathrm{NC}$, we are aware that no economic damage will be able to match the pain that the loss of a loved one brings to a family, community, and friends. While stay-athome orders and social distancing have had large economic impacts on the farming community in $\mathrm{NC}$, they first and foremost saved an uncountable number of lives.

\section{Acknowledgments}

We thank Dr. Chris Gunter (University of Florida, Department of Horticulture) and Drs. Gina Fernandez, Nancy Creamer, Barbara Fair, and Jeanine Davis (all NC State University, Department of Horticultural Science) for their impact on the development of survey questions and efforts to reach out to grower associations for survey distribution.

\section{References}

Anderson, M. D. (2020). Pandemic shows deep vulnerabilities. Agriculture and Human Values, 37, 559-560. https://doi.org/10.1007/s10460-020-10108-7 
Brown, C. (2015, May 11). Why aren't public service organizations customer-centric? MarketCulture. https://blog.marketculture.com/2015/05/11/why-arent-public-service-organizations-customer-centric/

Carolina Farm Stewardship Association (CFSA) (2020). From 'scrambling' to 'devastated': The impact of covid-19 on farms in North and South Carolina. https://www.carolinafarmstewards.org/wp-content/uploads/2020/06/CFSA-COVID-19-Survey-Report Final.pdf

Cranfield, J., Henson, S., \& Blandon, J. (2012). The effect and attitudinal and sociodemographic factors on the likelihood of buying locally produced food. Agribusiness, 28(2), 205-221. https://doi.org/10.1002/agr.21291

Cullen, M. T. (2020). COVID-19 and the risk to food supply chains: How to respond? Food and Agriculture Organization of the United Nations [FAO]. https://doi.org/10.4060/ca8388en

Havice, E., Marschke, M. \& Vandergeest, P. (2020). Industrial seafood systems in the immobilizing COVID-19 moment. Agriculture and Human Values, 37, 655-656. https://doi.org/10.1007/s10460-020-10117-6

Hendrickson, M. K. (2020). Covid lays bare the brittleness of a concentrated and consolidated food system. Agriculture and Human Values, 37, 579-580. https://doi.org/10.1007/s10460-020-10092-y

Hobbs, J. E. (2020). Food supply chains during the COVID-19 pandemic. Canadian Journal of Agricultural Economics/Revne canadienne d'agroeconomie, 68(2), 171-176. https://doi.org/10.1111/cjag.12237

Johnson, R. (2020). Covid-19: Supply chain disruptions in the U.S. fruit and vegetable industry: In brief. Congressional Research Service. https://crsreports.congress.gov/product/pdf/R/R46348

Lemos, M., \& Ackoff, S. (2020, April 28). Young farmers COVID-19 survey summary. National Young Farmers Coalition. https://www.youngfarmers.org/2020/04/covid19surveysummary/

Low, S. A., Adalja, A., Beaulieu, E., Key, N., Martinez, S., Melton, A., Perez, A., Ralston, K., Stewart, H., Suttles, S., Vogel, S., \& Jablonski, B. R. R. (2015). Trends in U.S. local and regional food systems (Report No. AP-068). U.S.

Department of Agriculture, Economic Research Service [USDA ERS]. https://www.ers.usda.gov/webdocs/publications/42805/51173 ap068.pdf

Lusk, J., Langemeier, M., \& Minert, J. (2020, April 21). COVID-19's impacts on US food and agriculture [Webinar]. Purdue University. https://extension.purdue.edu/article/36961

MacDonald, J. (2021, March 11). Small farms, big differences. U.S. Department of Agriculture [USDA]. https://www.usda.gov/media/blog/2010/05/18/small-farms-big-differences

NC Broadband Infrastructure Office. (2020). Broadband adoption potential in North Carolina counties [Interactive map]. https://bi.nc.gov/t/DITBroadband/views $/ 2017$ CountyIndices/BBADPStory?\%3AisGuestRedirectFromVizportal $=\mathrm{y} \& \% 3$ Aembed $=\mathrm{y}$

North Carolina Department of Agriculture and Consumer Services [NCDA \& CS]. (2020). Farmers market directory. https://www.ncfarmfresh.com/index.asp

North Carolina Executive Order 121. (2020, March 27). https://files.nc.gov/governor/documents/files/EO121-Stay-at-Home-Order-3.pdf

North Carolina State University. (2012). Our Vision. NC State Extension. https://www.ces.ncsu.edu/our-vision/

NCGOV. (n.d.). Face coverings and masks. Retrieved November 2020 from https://covid19.ncdhhs.gov/information/individuals-families-and-communities/face-coverings-and-masks

O'Hara, J. K., \& Lin, J. (2019). Population density and local food market channels. Applied Economic Perspectives and Policy, 42(3), 477-496. https://doi.org/10.1093/aepp/ppy040

O’Hara, J. K, \& Low, S. A. (2020). Online sales: A direct marketing opportunity for rural farms? Journal of Agricultural and Applied Economics, 52(2), 222-239. https://doi.org/10.1017/aae.2019.44

Patillo, A. R., Millsap, J. C., Byers, P., Gundel, J., Peregoy, K., Lake, A., Denkler, S., Meusch, E., \& Burton, D. (2021). Missouri's specialty crop beginning farmers cultivate resilience during COVID-19. Journal of Agriculture, Food Systems, and Community Development, 10(2), 225-239. https://doi.org/10.5304/jafscd.2021.102.052

Saksena, M. J., Okrent, A. M., Anekwe, T. D., Cho, C., Dicken, C., Effland, A., Elitzak, H., Gutherie, J., Hamrick, K. S., Hyman, J., Jo, Y., Lin, B. H., Mancino, L., McLaughlin, P. W., Rahkovsky, I., Ralston, K., Smith, T. A., Stewart, H., Todd, J., \& Tuttle, C. (2018). America's eating habits: Food away from home [Report summary]. U.S. Department of Agriculture. https://www.ers.usda.gov/webdocs/publications/90228/eib-196 summary.pdf 
U.S. Department of Agriculture, National Agricultural Statistical Service [USDA NASS]. (2015). 2015 local food marketing practices survey. Census of Agriculture. https://www.nass.usda.gov/Publications/AgCensus/2012/Online Resources/Local Food/index.php

USDA NASS. (2017). 2017 Census of agriculture: North Carolina state profile. https://www.nass.usda.gov/Publications/AgCensus/2017/Online Resources/County Profiles/North Carolina/c p99037.pdf

USDA NASS. United States census of agriculture 2017: Summary and state data. Vol. 1 geographic area series [Data set]. https://www.nass.usda.gov/Publications/AgCensus/2017/Full Report/Volume 1, Chapter_1 US/usv1.pdf

USDA National Institute of Food and Agriculture. (2020). Cooperative Extension System. https://nifa.usda.gov/cooperative-extension-system

White, N. E. (2021). Farming in the time of pandemic: Small farms demonstrate flexibility, innovation, and hope. Journal of Agriculture, Food Systems, and Community Development, 10(2), 247-249. https://doi.org/10.5304/jafscd.2021.102.008 